\title{
A Nation of Emigrants. How Mexico Manages its Migration
}

David Fitzgerald, 2009, Berkeley, University of California Press

\author{
Cecilia Imaz Bayona \\ Universidad Nacional Autónoma de México
}

David Fitzgerald, en su libro $A$ Nation of Emigrants. How Mexico Manages its Migration (Nación de emigrantes. Cómo México gestiona su migración), afirma que, a lo largo de la historia de la migración mexicana hacia Estados Unidos, ha habido diversas políticas estatales en relación con esos movimientos de población que no siempre han logrado su objetivo, y que las nuevas estrategias del Estado mexicano para acercarse a sus emigrados fuera del territorio nacional han resultado en una nueva forma voluntarista y limitada de ciudadanía que liga a los emigrantes con su país de origen.

El autor ofrece a los académicos y al público en general un interesante texto sobre la historia de la emigración mexicana al vecino país del norte. Con una visión histórica y tomando ejemplos de una comunidad emisora de migrantes de larga tradición: Arandas, en Los Altos de Jalisco, presenta un amplio panorama de esta más que centenaria migración, y centra su argumentación en los cambios de percepción y orientación en las políticas migratorias mexicanas, hasta llegar a la etapa actual, en que la construcción de una relación entre gobierno y diáspora ha conducido a transformaciones sociales en los campos de la soberanía y la ciudadanía.

Fitzgerald argumenta que la fusión del territorio, el gobierno y el pueblo en los Estados-nación ha sido resquebrajada por la emigración, como en el caso de México y de otros países emisores de migrantes, y esta realidad ha creado un tipo particular de Estadonación. Sin embargo, lo anterior no significa que el sistema westfaliano de Estados soberanos esté en declive. Por el contrario, es fuerte 
y ha asimilado el reto que representa la masiva migración internacional, que ha dado forma a un nuevo tipo de contrato social entre los emigrantes y el país de origen, figura que Fitzgerald denomina ciudadanía a la carta.

El concepto de ciudadanía a la carta trata de explicar un fenómeno relativamente reciente de la migración internacional, referido a los nuevos derechos ciudadanos de los migrantes, y que la sociología política de la migración ha explicado a través de los impactos de la salida, ausencia y retorno de los migrantes en la organización y desarrollo del Estado-nación, en los derechos ciudadanos y en la transformación de la sociedad.

Con diferentes motivaciones, los países emisores de migrantes han abrazado a sus connacionales ausentes y, al hacerlo, han reforzado sus capacidades políticas internas e internacionales.

Atinadamente, Fitzgerald distingue la ciudadanía extraterritorial del transnacionalismo, pues la primera es un derecho reconocido a los emigrantes, mientras que el transnacionalismo es una manifestación del nacionalismo a larga distancia. También señala que el marco que conecta la ciudadanía móvil con el Estado y la nación no es totalmente nuevo; tiene prece- dentes en movimientos migratorios masivos, pero la diferencia es que no había sido comprendida su conceptualización analítica sino hasta ahora.

A lo largo de cinco capítulos, Fitzgerald guía al lector a través de los intentos que por siete décadas (de 1900 a 1970) siguieron los gobiernos mexicanos para controlar el volumen, la duración de las estancias, las capacitaciones laborales y el origen geográfico de los emigrantes.

Frente al fracaso de las medidas-que incluyeron campañas de propaganda para impedir la emigración, los programas Bracero, la negativa a expedir documentos de viaje a ciertas ocupaciones y categorías geográficas de trabajadores, y aun la coerción en la frontera-, los gobiernos mexicanos, desde finales de los años ochenta, cambiaron su orientación hacia la emigración con un enfoque en la gestión de los emigrantes que residen en el extranjero o que visitan México.

En el capítulo uno, el autor describe cómo los problemas y posibilidades que crea la migración internacional en los hogares afectados en los países de inmigración generan, a su vez, retos y oportunidades en los países de origen. Fitzgerald retoma una dis- 
cusión entre los estudiosos de este tema que argumentan las formas en que la globalización, a través de la migración internacional, ha impactado negativamente el poder de los Estados. Refuta esta interpretación así como aquella que sostiene contrariamente que los Estados no han sido impactados por la migración. Él argumenta que la migración sí ha alterado los tres pilares del Estado-nación (gobierno, pueblo y territorio), pero que tales transformaciones muestran que el principio internacional de la soberanía exclusiva del Estado sobre su territorio permanece fuerte, a pesar de los grandes flujos de personas entre países.

En el capítulo dos, el autor trata los cambios de orientaciones y políticas respecto a la emigración en el siglo pasado en México, en los ámbitos federal, estatal y local, y cómo han tenido que adaptarse ante la realidad impuesta por la enorme interdependencia asimétrica con Estados Unidos, así como por las políticas migratorias de ese país y las transformaciones demográficas de México.

Resulta muy interesante el análisis de cómo el Estado mexicano adoptó las prácticas de membresía que tiempo atrás había iniciado la Iglesia Católica con los migrantes. De esto trata el capítulo tres.
En un principio, Iglesia y Estado intentaron, de manera independiente, disuadir la emigración por los efectos negativos en el poblamiento de comunidades y por la pérdida de los valores morales y culturales de las familias afectadas por el fenómeno migratorio. Ante el fracaso de tales intentos, la Iglesia cambió de enfoque y se dedicó a la gestión en favor de los migrantes, a la asistencia social, a su organización y registro, en lugar de tratar de controlar y detener los flujos migratorios. Ante el éxito de estas nuevas medidas, el Estado adoptó las estrategias organizacionales de la Iglesia para una mejor gestión de los asuntos relacionados con los migrantes, reforzando el modelo de redes voluntarias y con una membresía móvil.

En el capítulo cuarto, el autor muestra cómo el tema de los clubes sociales de migrantes por lugar de origen no es nuevo. Tomando el ejemplo de la comunidad migrante de Arandas, Jalisco, reseña que, desde los años cuarenta, los migrantes arandenses en las grandes ciudades de México se organizaron en clubes sociales, que posteriormente fueron el fundamento de los clubes de migrantes por lugar de origen. Establecidos después en Estados Unidos, estos clubes lograron, entre muchos 
otros beneficios, institucionalizar las ligas entre los emigrados y el gobierno mexicano.

Este recuento histórico de Fitzgerald sobre los clubes sociales de migrantes por lugar de origen -que fueron organizados inicialmente por la Iglesia Católica-, los procesos seguidos por la Iglesia y el Estado mexicano en su relación con los emigrados, así como su propuesta respecto a las nuevas formas de ciudadanía, constituyen aportaciones importantes en la explicación de este campo de la investigación sobre temas migratorios.

En el quinto capítulo, intitulado "¿El extranjero o el hijo pródigo?", el autor se separa de la tendencia tradicional de estudiar a los migrantes en el país de arribo bajo el enfoque de la integración o la asimilación cultural. El autor examina la desasimilación cultural de los emigrantes, un tema recurrente en el libro y en las entrevistas durante el trabajo de campo en Jalisco, Chicago y California.

Fitzgerald apunta la ambivalencia común entre los mexicanos respecto a la percepción de los efectos culturales negativos de la migración frente a sus efectos económicos positivos del fenómeno, y sugiere que esa ambivalencia representa una limitación adicional en los intentos de los representan- tes políticos interesados en ampliar los reclamos de pertenencia de los migrantes para incluirlos como miembros del Estado-nación fuera de su territorio.

El libro concluye con un análisis de cómo ha enfrentado el gobierno mexicano los retos de la emigración $y$, en menor medida, las oportunidades para construir el Estado y la nación.

El autor se concentra en 10 campos centrales de políticas públicas en los cuales la migración ha tenido una importancia fundamental.

Siguiendo a Charles Tilly (1975, The Formation of National States in Western Europe, Nueva Jersey, Princeton University Press), Fitzgerald hace referencia a tales campos: política laboral, gobierno, finanzas, seguridad social, registro estadístico, educación, cultura nacional, reclutamiento militar, estabilidad política y relaciones internacionales. De estos campos, el laboral es en donde resulta más evidente la falta de cohesión del Estado mexicano, pues las políticas que más han impactado a la migración no han sido las migratorias sino las políticas agrarias y demográficas, además de las secuelas de guerras civiles y crisis económicas vividas.

El apoyo metodológico de este trabajo, además del análisis docu- 
mental y de archivos históricos, fue una encuesta aplicada en 97 hogares de Agua Negra, 200 en Arandas y una muestra de bola de nieve en diversos puntos entre hogares arandenses en Chicago y en el condado de Orange, California, utilizando el cuestionario estándar y la metodología del Mexican Migration Proyect (MMP), coordinado por las universidades de Princeton y de Guadalajara. Con el apoyo del equipo del MMP se recolectaron historias laborales y de migración en 317 hogares, y se obtuvieron datos de 1503 personas.

Para el punto de vista tradicional norteamericano respecto a la inmigración mexicana, este trabajo contribuye a derribar mitos como el de la llamada estrategia de Aztlán, que los detractores de la inmigración mexicana han difundido extensamente en los medios. Este restringido punto de vista sostiene que la intención última de la inmigración de mexicanos consiste en retomar los territorios perdidos en la guerra de 1848 e invadir poblacional y culturalmente gran parte de Estados Unidos. Esta alarmante visión ha tenido un efecto dañino en la relación bilateral y ha contribuido a atrasar la concreción de una reforma migratoria norteamericana.
Igualmente, el autor objeta el argumento de que las políticas migratorias de México amenacen la soberanía estadounidense. Sostiene que sucede lo contrario, pues la mayoría de las medidas retentivas que ha intentado aplicar el Estado mexicano han fracasado, en gran parte, precisamente por la fuerza de la soberanía norteamericana, que impone sus leyes y prácticas migratorias, y por las consecuencias no intencionadas de éstas.

Desde el punto de vista mexicano, este trabajo contribuye a un mayor conocimiento de la historia de la migración nacional, de las diferentes percepciones sobre ella a lo largo de siglo y medio, y de las políticas estatales que han intentado aplicarse. Resulta interesante destacar las contradicciones entre las aspiraciones que tuvieron varios gobiernos para detener el éxodo masivo de migrantes, y las orientaciones culturales en las comunidades expulsoras de éstos, por lo general, altamente proclives a la emigración.

La lectura de este libro es muy recomendable e ilustrativa, tanto por el material histórico que aporta, como por las sugerentes argumentaciones en torno a las nuevas formas de ciudadanía producidas por la migración internacional. 